\title{
ANALISIS FAKTOR-FAKTOR YANG MEMPENGARUHI MOTIVASI KERJA PERAWAT DI RUMAH SAKIT UMUM YARSI PONTIANAK
}

\author{
Yunita Dwi Anggreini ${ }^{1 *}$, Wahyu Kirana ${ }^{2}$, Ratih Diyan Kumalasari ${ }^{3}$ \\ ${ }^{1-3}$ STIKes YARSI Pontianak \\ Yunita Dwi Anggreini: STIKes YARSI Pontianak, Jln. Panglima A'im No. 1, \\ Kota Pontianak, Kalimantan Barat - 78232, E-mail: yunita.anggreini@gmail.com
}

\begin{abstract}
Abstrak
Perawat adalah sumber daya utama dan merupakan bagian penting dari pemberian layanan dalam sistem kesehatan. Motivasi dan kinerja perawat profesional menentukan kualitas kesehatan pasien dan memiliki pengaruh signifikan terhadap keberhasilan rumah sakit. Oleh karena itu, kebutuhan motivasi perawat sangat penting dalam menentukan kualitas layanan yang diberikan. Penelitian ini bertujuan untuk menganalisis faktor-faktor yang memengaruhi motivasi kerja perawat di Rumah Sakit Umum YARSI Pontianak. Jenis penelitian yang digunakan adalah penelitian korelasional dengan pendekatan cross sectional. Sampel dalam penelitian ini terdiri dari 32 orang perawat di ruang rawat inap Rumah Sakit YARSI Pontianak. Uji statistik yang digunakan adalah uji chi square untuk mengetahui hubungan bivariat antar variabel dan uji regresi logistik berganda untuk menganalisis faktor yang paling memengaruhi motivasi kerja perawat. Hasil analisis statistik menunjukkan faktor prestasi, pengakuan, hubungan pekerjaan itu sendiri, tanggung jawab dan pengembangan potensi individu mempunyai hubungan yang signifikan terhadap motivasi kerja perawat sedangkan faktor yang paling dominan berpengaruh adalah prestasi (wald $=4,130)$.
\end{abstract}

Kata Kunci : Prestasi, tanggung jawab, pengakuan, pengembangan potensi individu, hubungan pekerjaan, motivasi kerja

\section{Abstract}

Nurse is a main resource and is an important part of health system services. Nurse's motivation and performance determine the quality of patient's health and have significant influence toward the success of the hospital. Therefore, nurse's motivation is very important in order to specify the quality of the service given. This research aims to analyze the factors that influence the nurse's work motivation in YARSI Pontianak public hospital. This research used non experimental research with cross sectional approach. The sample consists of 32 nurses in the inpatient room of YARSI Pontianak public hospital. The test analysed statistically using chi square test to determine bivariat correlation and doubled logistic regression to analyse the most influence factor toward nurse's work motivation. The result of statistic analysis showed achievement, recognition, work itself-client relationship, responsibility and advancement have significant relationship toward nurse's work motivation while the most influence factor was achievement $($ wald $=4.130)$.

Keywords: Achievement, responsibility, recognition, advancement, work itself-client relationship, work motivation

\section{PENDAHULUAN}

Sistem perawatan dan kesehatan memainkan peran penting dalam pembangunan berkelanjutan setiap masyarakat karena berhubungan langsung dengan kesehatan manusia. Untuk memenuhi tujuan ini, dibutuhkan tenaga kesehatan yang sehat dan bahagia serta memiliki motivasi kerja yang tinggi (Kouchaki, 2016).
Perawat adalah sumber daya utama dan merupakan bagian penting dari pemberian layanan dalam sistem kesehatan. Motivasi dan kinerja perawat profesional menentukan kualitas kesehatan pasien dan memiliki pengaruh signifikan terhadap keberhasilan rumah sakit. Oleh karena itu, kebutuhan motivasi perawat sangat penting dalam menentukan kualitas layanan yang diberikan (Jooste \& Hamani, 2016). 
berkualitas dan berkontribusi pada

Motivasi adalah faktor besar dalam menentukan tingkat kinerja karyawan dan kualitas pencapaian tujuan. William James dari Harvard melakukan penelitian tentang motivasi dan menyimpulkan bahwa karyawan setiap jam dapat mempertahankan pekerjaan mereka dengan hanya bekerja 20\% - 30\% dari kapasitas mereka. Namun, ketika mereka termotivasi dengan baik, mereka dapat bekerja 80\%-90\% dari kemampuan mereka (Rigolosi, 2013).

Motivasi memungkinkan seseorang untuk menunjukkan potensinya, dan bahkan dapat melakukan sesuatu melampaui apa yang diharapkan dari kecerdasan dan kemampuan akademiknya. Perawat adalah aset bagi organisasi pelayanan kesehatan.

Motivasi dan faktor-faktornya adalah alat manajemen yang efektif untuk menarik, mempertahankan, dan meningkatkan kinerja perawat. Motivasi kerja adalah prasyarat untuk kinerja organisasi yang lebih baik. Hal tersebut diilustrasikan sebagai "proses yang menjelaskan intensitas, arah, dan kegigihan individu untuk mencapai tujuan". Sebagai aturan umum, "motivasi berasal dari kebutuhan yang dapat memenuhi, dan mengarah pada perilaku tertentu (Alhakami \& Baker, 2018).

Perawat perlu dimotivasi untuk menyelesaikan tugas mereka, memberikan perawatan yang pengembangan profesi keperawatan. Kurangnya motivasi dapat menyebabkan ketidakpuasan di antara pekerja, kurangnya kebanggaan dalam pekerjaan mereka, tidak merasa bagian dari rumah sakit, niat untuk keluar dari rumah sakit dan / atau profesi keperawatan, dan meningkatkan tingkat stres kerja. Kurangnya kontrol yang dirasakan atas faktor-faktor yang mempengaruhi standar praktik dapat menyebabkan ketidakpuasan, frustrasi, dan demoralisasi (Kamanzi \& Nkosi, 2011).

Pada dasarnya faktor-faktor motivasi dikelompokkan menjadi dua kelompok yaitu faktor internal dan faktor eksternal. Berdasarkan teori motivasi Herzberg, faktor internal terdiri dari prestasi (achievement), pengakuan (recognition), pekerjaan itu sendiri-hubungan klien (work itself-client relationship), tanggung jawab (responsibility), pengembangan potensi individu (advancement) (Badubi, 2017). Penelitian yang dilakukan oleh Cumber \& Elive (2016) menunjukkan bahwa faktor internal menjadi faktor yang paling dominan yang mempengaruhi motivasi perawat.

Hasil penelitian oleh Vionita (2010) menyatakan bahwa $80-90 \%$ prestasi kerja manusia tergantung kepada motivasinya untuk bekerja dan 10-20\% tergantung kepada kemampuannya. Selanjutnya $50 \%$ motivasi kerja dipengaruhi oleh motivasi pekerja itu 
sendiri tergantung pada kondisi sosial, yaitu sebagai makhluk sosial yang memerlukan interaksi dengan orang lain serta lingkungannya, misalnya kebutuhan untuk bersaing, bersahabat, dan berekspresi. Kemudian $40 \%$ tergantung kepada kebutuhankebutuhan, seperti kebutuhan untuk berprestasi, pengembangan diri, serta penghargaan. Sedangkan $10 \%$ tergantung pada kondisi fisik seperti haus, lapar, tempat tinggal (kondisi fisik ini timbul dengan sendirinya/sudah ada sejak manusia lahir).

Pernyataan tersebut membuktikan bahwa untuk meningkatkan produktifitas perawatnya, maka perlu dipertimbangkan bukan hanya pada kebutuhan fisiologisnya, akan tetapi lingkungan kerja yang menyenangkan, beban kerja yang seimbang, upah yang adil, pengawasan yang baik dan bijaksana, kesempatan untuk berprestasi, keselamatan kerja, serta kompensasi-kompensasi lain yang memadai.

\section{METODE}

Jenis penelitian yang digunakan adalah penelitian korelasional dengan pendekatan cross sectional. Sampel dalam penelitian ini sebanyak 32 orang perawat di rawat inap Rumah Sakit YARSI Pontianak. Instrumen penelitian berupa kuesioner yang terdiri dari data demografi, kuesioner prestasi, pengakuan, hubungan pekerjaan, tanggung jawab, pengembangan potensi individu dan motivasi kerja. Uji validitas menggunakan uji pearson product moment. Hasil uji validitas dan reliabilitas yang dilaksanakan di RS Anton Soedjarwo Pontianak kepada 30 responden didapatkan nilai $r$ hasil berentang antara 0,3650,731 (>r tabel 0,361) hal ini menunjukan bahwa seluruh item pertanyaan dinyatakan valid dan mempunyai nilai reliabilitas yang handal 0,782 $(>0,60)$. Analisa data yang digunakan adalah analisis univariat untuk menggambarkan variabel penelitian secara deskriptif dalam bentuk distribusi frekuensi, analisis bivariat menggunakan uji chi square dan analisis multivariat menggunakan analisis regresi logistik berganda.

\section{HASIL}

1. Analisis univariat

Tabel 1 memberikan gambaran temuan penelitian yang berkaitan dengan karakteristik responden yang meliputi umur, pendidikan, prestasi kerja, pengakuan, pekerjaan, tanggung jawab, potensi individu dan motivasi kerja.

Tabel 1. Karakteristik Perawat Unit Rawat Inap Rumah Sakit Yarsi Pontianak April 2018, $(\mathrm{n}=32)$

\begin{tabular}{lll}
\hline \multicolumn{1}{c}{ Vairabel dan Katagori } & f & $\%$ \\
\hline Umur & & \\
26-35 thn & 25 & 78,1 \\
$36-45$ thn & 7 & 21,9 \\
\hline Pendidikan & & \\
Diploma III Keperawatan & 22 & 68,8 \\
Sarjana & 10 & 31,2 \\
\hline Prestasi & & \\
Baik & 27 & 84,4 \\
Tidak Baik & 5 & 15,6 \\
\hline Pengakuan & & \\
Tinggi & 23 & 71,9 \\
Rendah & 9 & 28,1 \\
\hline
\end{tabular}




\begin{tabular}{lll}
\hline Pekerjaan & 25 & 78,1 \\
Baik & 7 & 21,9 \\
Tidak Baik & 28 & 87,5 \\
\hline Tanggung Jawab & 4 & 12,5 \\
Baik & & \\
Tidak Baik & & \\
\hline Pengembangan & Potensi & \\
Individu & 24 & 72 \\
Baik & 8 & 28 \\
Tidak Baik & & \\
\hline Motivasi Perawat & 26 & 81,2 \\
Tinggi & 6 & 18,8 \\
Rendah &
\end{tabular}

Sumber : data primer (2018)

Berdasarkan tabel 1 diatas, sebagian besar responden berusia 26-35 tahun 78,1\%, Pendidikan Diploma III keperawatan 68,8\%, prestasi baik $84,4 \%$, pengakuan yang tinggi $71,9 \%$, pekerjaan yang baik $78,1 \%$, tunggung jawab yang baik $87,5 \%$, pengembangan potensi individu yang baik $72 \%$ dan motivasi perawat yang tinggi $81,2 \%$.

\section{Analisis bivariat}

Tabel 2 menunjukkan bahwa hubungan setiap variabel dengan motivasi perawat yang bekerja di rumah sakit.

Tabel 2. Hubungan prestasi, pengakuan, pekerjaan, tanggung jawab, dan potensi terhadap motivasi kerja perawat Unit Rawat Inap Rumah Sakit Yarsi Pontianak April 2018, $(\mathrm{n}=32)$

\begin{tabular}{|c|c|c|c|c|c|c|}
\hline \multirow{3}{*}{$\begin{array}{l}\text { Variabel dan } \\
\text { Katagori }\end{array}$} & \multicolumn{4}{|c|}{ Motivasi Kerja Perawat } & \multirow{3}{*}{$\begin{array}{l}\mathrm{N} \\
\text { total }\end{array}$} & \multirow{3}{*}{$\begin{array}{l}P \\
\text { value }\end{array}$} \\
\hline & \multicolumn{2}{|c|}{$\begin{array}{l}\text { Tidak } \\
\text { Baik }\end{array}$} & \multicolumn{2}{|c|}{ Baik } & & \\
\hline & $\mathrm{N}$ & $\%$ & $\mathrm{~N}$ & $\%$ & & \\
\hline Prestasi & & & & & & 0,001 \\
\hline Baik & 4 & 12,5 & 23 & 71,9 & 27 & \\
\hline Tidak Baik & 2 & 6,2 & 3 & 9,4 & 5 & \\
\hline Pengakuan & & & & & & 0,002 \\
\hline Tinggi & 1 & 3,1 & 22 & 68,8 & 23 & $*$ \\
\hline Rendah & 5 & 15,6 & 4 & 12,5 & 9 & \\
\hline Pekerjaan & & & & & & \\
\hline Baik & 2 & 6,2 & 18 & 56,3 & 25 & \\
\hline
\end{tabular}

\begin{tabular}{|c|c|c|c|c|c|c|}
\hline Tidak Baik & 4 & 12,5 & 8 & 25 & 7 & $\begin{array}{l}0,008 \\
*\end{array}$ \\
\hline \multicolumn{7}{|l|}{$\begin{array}{l}\text { Tanggung } \\
\text { Jawab }\end{array}$} \\
\hline Baik & 5 & 15,6 & 23 & 71,9 & 28 & \multirow{2}{*}{$\begin{array}{l}0,000 \\
*\end{array}$} \\
\hline Tidak Baik & 1 & 3,1 & 3 & 9,4 & 4 & \\
\hline \multicolumn{7}{|l|}{ Potensi } \\
\hline Baik & 4 & 12,5 & 20 & 62,5 & 24 & \\
\hline Tidak Baik & 2 & 6,2 & 6 & 18,8 & 8 & \\
\hline
\end{tabular}

Sumber : data primer (2018)

Berdasarkan tabel diatas, didapatkan hasil bahwa terdapat hubungan yang bermakna antara prestasi dengan motivasi kerja perawat $p$ value $=0,001<0,05$, pengakuan dengan motivasi kerja perawat $p$ value $=0,002<0,05$, pekerjaan dengan motivasi kerja perawa $p$ value $=0,008<$ 0,05 , tanggung jawab dengan motivasi kerja perawat $p$ value $=0,000<0,05$ dan pengembangan potensi individu dengan motivasi kerja perawat $p$ value $=0,005<0,05$.

\section{Analisis multivariat}

Setelah melalui beberapa tahapan sebelumnya, didapatkan model terakhir pada tabel 3 yang menjelaskan faktor mana yang paling berpengaruh terhadap motivasi kerja perawat.

Tabel 3. Faktor yang paling dominan mempengaruhi motivasi kerja perawat Unit Rawat Inap Rumah Sakit Yarsi Pontianak Juli 2018, $(n=32)$

\begin{tabular}{|c|c|c|c|c|c|c|}
\hline \multirow[t]{2}{*}{ Variabel } & \multirow[t]{2}{*}{ B } & \multirow{2}{*}{$\begin{array}{l}\text { Wa } \\
\text { ld }\end{array}$} & \multirow[t]{2}{*}{ Sig. } & \multirow{2}{*}{$\begin{array}{l}\operatorname{Exp}(B \\
)\end{array}$} & \multicolumn{2}{|c|}{$\begin{array}{l}95 \% \text { C.I for EXP } \\
\text { (B) }\end{array}$} \\
\hline & & & & & Lower & Upper \\
\hline Prestasi & 2,415 & 4.130 & 0,042 & 11,191 & 1,090 & 14,931 \\
\hline Pengakuan & 1,736 & 1,083 & 0,298 & 5,675 & 0,216 & 49,365 \\
\hline Pekerjaan & ),393 & 0,035 & 0,852 & 1,482 & 0,024 & 91,399 \\
\hline $\begin{array}{l}\text { Tanggungja } \\
\text { wab }\end{array}$ & ), 273 & 0,055 & 0,814 & 1,313 & 0,135 & 12,811 \\
\hline $\begin{array}{l}\text { Pengemban } \\
\text { gan }\end{array}$ & ),645 & 0,158 & 0,691 & 1,907 & 0,079 & 45,779 \\
\hline
\end{tabular}


Berdasarkan nilai Wald $=4,130$ statistik, variabel yang paling dominan pengaruhnya terhadap motivasi kerja perawat adalah prestasi.

\section{PEMBAHASAN}

1. Analisis Univariat

Hasil penelitian menunjukkan bahwa sebagian besar perawat di RS YARSI berusia 26-35 tahun (dewasa awal), sebagian besar perawat memiliki pendidikan Diploma III, sebagian besar perawat mempunyai prestasi yang baik, sebagian besar perawat mendapatkan pengakuan yang tinggi, sebagian besar perawat mempunyai hubungan pekerjaan yang baik, sebagian besar perawat mempunyai tanggung jawab yang baik dan sebagian besar perawat mempunyai motivasi kerja yang tinggi.

Hal ini sejalan dengan penelitian yang dilakukan oleh Sayed \& Ali (2017), dimana sebagian besar perawat berusia 20 tahun keatas dan sebagian besar perawat mempunyai pendidikan Diploma, sebagian besar perawat mempunyai prestasi yang baik. Penelitian yang dilakukan oleh Kamanzi \& Nkosi (2011) menunjukkan bahwa sebagian besar perawat berusia 25-35 tahun.

\section{Analisis Bivariat}

Analisis bivariat menunjukkan terdapat hubungan yang signifikan antara prestasi, pengakuan, hubungan pekerjaan, tanggung jawab dan pengembangan potensi individu dengan motivasi kerja perawat.
Hasil penelitian yang mendukung penelitian ini dilakukan oleh Cahyani, et al (2016), yaitu terdapat hubungan antara prestasi kerja, pengakuan, hubungan pekerjaan, tanggung jawab dan pengembangan potensi individu dengan motivasi kerja pada perawat Rumah Sakit Jiwa Daerah Dr. Amino Gondohutomo Provinsi Jawa Tengah.

Hal ini didukung oleh teori yang dikemukakan oleh Herzberg, yang menyatakan bahwa semakin tinggi faktor motivasi seperti prestasi kerja, pengakuan, hubungan pekerjaan, tanggung jawab dan pengembangan potensi individu maka akan semakin tinggi pula motivasi kerja seseorang (Baah, 2011).

Motivasi intrinsik adalah dorongan dari dalam diri individu yang menuntun seseorang untuk mencapai tujuan personal dan organisasi serta mendorong individu untuk melakukan aktivitas yang disenangi (Baljoon, et al, 2018).

\section{Analisis Multivariat}

Analisis multivariat didapatkan faktor yang paling berpengaruh terhadap motivasi kerja perawat di Rumah Sakit Umum YARSI Pontianak adalah prestasi, dengan nilai Wald = 4,130 .

Adanya kebutuhan dasar seseorang dalam bekerja seperti prestasi, pengakuan, hubungan pekerjaan, tanggung jawab dan pengembangan potensi individu mempengaruhi motivasi dari individu tersebut (Daft \& Marcic, 2009). 


\section{KESIMPULAN}

Dari hasil penelitian dapat diketahui bahwa variabel prestasi, pengakuan, hubungan pekerjaan itu sendiri, tanggung jawab dan pengembangan potensi individu mempunyai hubungan yang signifikan dengan motivasi kerja perawat di Rumah Sakit Umum YARSI Pontianak. Faktor yang paling berpengaruh terhadap motivasi kerja perawat adalah prestasi.

Dalam penelitian initerdapat keterbatasan dalam jumlah sampel penelitian, sehingga perlu dilakukan penelitian dengan jumlah sampel yang lebih besar.

\section{UCAPAN TERIMA KASIH}

Penelitian ini dapat terlaksana tidak terlepas dari dukungan dari berbagai pihak, oleh karena itu kami sampaikan terima kasih kami kepada:

1. Ibu Fajar Yousriatin, M.Kes selaku Ketua STIKes YARSI Pontianak yang telah memberikan dukungan dalam proses pengajuan permohonan dan perijinan tempat penelitian

2. Ibu Ns. Diena Juliana, S.Kep., M.Kes selaku Ketua Lembaga Penelitian dan Pengabdian Masyarakat (LPPM) STIKes YARSI Pontianak yang telah membantu memfasilitasi publikasi hasil penelitian ini.

3. Direktur Rumah Sakit Umum YARSI Pontianak yang telah memberikan ijin dan memfasilitasi pelaksanaan penelitian.
4. Seluruh responden yang telah bersedia meluangkan waktunya untuk terlibat dalam proses penelitian ini.

\section{REFERENSI}

Alhakami, Ibrahim Yahya \& Baker, Omar Ghazi. 2018. Exploring the Factors Influencing Nurse's Work Motivation. Iris Journal of Nursing \& Care. 1 (1)

Baah, Kwasi Dartey. 2011. Application of Frederick Herzberg's Two-Factor Theory in Assessing and Understanding Employee Motivation at Work : A Ghanaian Perspective. European Journal of Business and Management, Vo. 3, No. 9

Badubi, Reuben M. 2017. Theories of Motivation and Their Application in Organizations : A Risk Analysis. International Journal of Innovation and Economic Development. 3 (3), pp. 44-51

Baljoon, Reem A, et al. 2018. Nurses' Work Motivation and the Factors Affecting It : A Scoping Review. International Journal of Nursing \& Clinical Practices. 5 : 277

Cahyani, Intan Dwi dkk. 2016. Faktor-Faktor yang Berhubungan dengan Motivasi Kerja pada Perawat Rumah Sakit Jiwa. Jurnal Kesehatan Masyarakat. Vol. 4, No. 2

Cumber, Samuel Nabile \& Elive, Stanly Mbua. 2016. The Identification of Motivational Factors That Influnces Nurses Output in Hospitals in the Fako Division, Cameroon. Journal of Family Medicine and Health Care. 2 (4), 74-80

Daft, Richard L \& Marcic, Dorothy. 2009. Understanding Management, Sixth Edition. USA : South-Western Cengage Learning

Jooste, Karien \& Hamani, Mida. 2016. The Motivational Needs of Primary Health Care Nurses to Acquire Power as Leaders in A Mine Clinic Setting. Elsevier on Behalf of Johannesburg University : 43-51 
Kamanzi, J \& Nkosi, Z. Z. 2011. Motivation Levels among Nurses Working at Butare University Teaching Hospital, Rwanda. Africa Journal of Nursing and Midwifery 13 (2), pp. 119-1321

Kouchaki, E et al. 2016. Correlation Between Anger and Job Motivation among Psychiatric Nurses in Kashan Psychiatric Hospital. International Archives of Health Sciences, Volume 3, Issue 4.

Rigolosi, Elaine La Monica. 2013. Management and Leadership in Nursing and Health Care : An Experiential Approach Third Edition. New York : Springer Publishing Company

Sayed, Rasha Ibrahim El \& Ali, Maha Ramadan. 2017. Achievement Motivation and Its Relation to Nurses' Decision Making Beliefs, Ability and Job Burnout at Obstretic and Gynecological Departments. Clinical Nursing Studies. Vol. 5, No. 4

Vionita Vony 2010, analisis Faktor-Faktpr Yang Berhubungan dengan Persepsi Perawat terhadap Kinerja Di Unit Perawatan Kelas III RS Pasar Rebo 